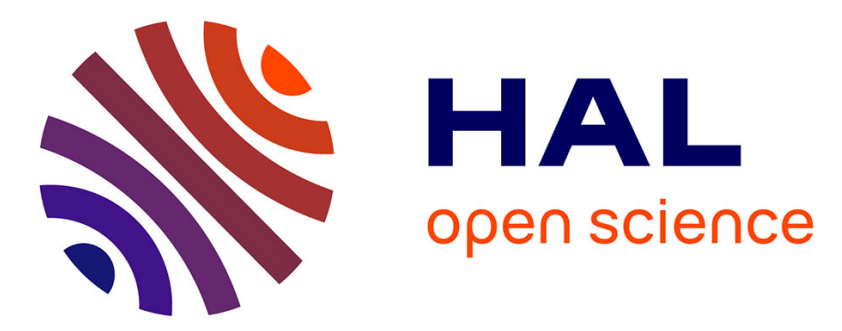

\title{
Genome analysis of Crassaminicella sp. SY095, an anaerobic mesophilic marine bacterium isolated from a deep-sea hydrothermal vent on the Southwest Indian Ridge
}

Xue-Gong Li, Wei-Jia Zhang, Xiao-Qing Qi, Long Fei Wu

\section{To cite this version:}

Xue-Gong Li, Wei-Jia Zhang, Xiao-Qing Qi, Long Fei Wu. Genome analysis of Crassaminicella sp. SY095, an anaerobic mesophilic marine bacterium isolated from a deep-sea hydrothermal vent on the Southwest Indian Ridge. Marine Genomics, 2019, pp.100733. 10.1016/j.margen.2019.100733. hal-02473056

\section{HAL Id: hal-02473056 \\ https://hal-amu.archives-ouvertes.fr/hal-02473056}

Submitted on 10 Feb 2020

HAL is a multi-disciplinary open access archive for the deposit and dissemination of scientific research documents, whether they are published or not. The documents may come from teaching and research institutions in France or abroad, or from public or private research centers.
L'archive ouverte pluridisciplinaire HAL, est destinée au dépôt et à la diffusion de documents scientifiques de niveau recherche, publiés ou non, émanant des établissements d'enseignement et de recherche français ou étrangers, des laboratoires publics ou privés. 
1 Genome analysis of Crassaminicella sp. SY095, an anaerobic

2 mesophilic marine bacterium isolated from a deep-sea 3 hydrothermal vent on the Southwest Indian Ridge

4 Xue-Gong $\mathrm{Li}^{1 ; 2 ; 3^{*}}$, Wei-Jia Zhang ${ }^{1 ; 2 ; 3}$, Xiao-Qing Qi ${ }^{1 ; 2 ; 3}$, and Long-Fei $\mathrm{Wu}^{2 ; 4}$

51 Laboratory of Deep-Sea microbial cell biology, Institute of Deep-sea Science and

6 Engineering, Chinese Academy of Sciences, China

72 France-China Joint Laboratory for Evolution and Development of Magnetotactic

8 Multicellular Organisms (LIA-MagMC), Marseille, France / IDSSE-CAS, Sanya,

9 China

103 Laboratory for Experimental Study under Deep-sea Extreme Conditions, Institute of

11 Deep-sea Science and Engineering, Chinese Academy of Sciences, China

124 Aix-Marseille Université, CNRS, LCB UMR 7257, IMM, Marseille, France

13 Running title: The first complete genome sequence of Crassaminicella.

$14 *$ Corresponding author

15 Xue-Gong Li

16 Deep Sea microbial cell biology, IDSSE, CAS,

17 Sanya 572000, China.

18 E-mail: xuegongli@idsse.ac.cn

19 Phone: 0086-898-8821 2769 
22 Abbreviations: CDS, coding sequence; COG, clusters of orthologous groups; GO, 23 gene ontology; KEGG, Kyoto Encyclopedia of Genes and Genomes; ORF, open 24 reading frame 


\section{Abstract}

Crassaminicella sp. strain SY095 is an anaerobic mesophilic marine bacterium that was recently isolated from a deep-sea hydrothermal vent on the Southwest Indian Ridge. Here, we present the complete genome sequence of strain SY095. The genome consists of a chromosome of 3,046,753 bp (G+C content of $30.81 \%)$ and a plasmid of 36,627 bp ( $\mathrm{G}+\mathrm{C}$ content of $31.29 \%$ ), encodes 2966 protein, 135 tRNA genes, and 34 rRNA genes. Numerous genes are related to peptide transport, amino acid metabolism, motility, and sporulation. This agrees with the observation that strain SY095 is a spore-forming, motile, and chemoheterotrophic bacterium. Further, the genome harbors multiple prophages that carry all the genes necessary for viral particle synthesis. Some prophages carry additional genes that may be involved in the regulation of sporulation. This is the first reported genome of a bacterium from the genus Crassaminicella, providing insights into the microbial adaptation strategies to the deep-sea hydrothermal vent environment.

Keywords: chemoheterotroph, chemoorganotroph, extreme environment, genome sequencing, prophage, sporulation 


\section{Introduction}

Deep-sea hydrothermal vent environment is characterized by steep temperature and geochemical gradients, which provide a large range of habitats for chemotrophic microorganisms [1]. Chemosynthetic bacteria and archaea utilize chemical energy to fix inorganic carbon into organic carbon for microbial growth, and form the foundation of vent ecosystems [2,3]. Chemotrophs are an important component of the microbial community in the deep-sea hydrothermal vent, and play critical roles in deep-sea carbon, nitrogen and sulfur cycling $[4,5]$.

The genus Crassaminicella is affiliated with Clostridiales and was first reported in 2015 [6]. It represents a novel type of mesophilic chemoorganotrophic bacteria from the deep-sea hydrothermal environment. Cells from this genus are gram stain-positive, motile, straight or curved rods, and form terminal endospores. Crassaminicella is an obligate anaerobic and heterotrophic bacterium that ferments carbohydrates and proteinaceous substrates [6]. To date, this genus contains only one species, Crassaminicella profunda, the sole strain Ra1766HT, as the type strain of this species, was isolated from sediments of the Guaymas Basin at a depth of 2002 m [6]. During the recent cruise, we have isolated an anaerobic mesophilic marine bacterium, strain SY095, from a deep-sea hydrothermal vent on the Southwest Indian Ridge. Phylogenetic analysis based on 16S rRNA gene sequences indicated that strain SY095 was most closely related to the type strain of C. profunda Ra1766HT $(96.05 \%$ similarity). Notably, the reported bacteria from the deep-sea hydrothermal vent environment mainly represent gram-negative bacteria. Only a few represent 
gram-positive bacteria, e.g., Clostridium tepidiprofundi $\mathrm{SG} 508^{\mathrm{T}}$ [7], Vulcanibacillus modesticaldus $\mathrm{BR}^{\mathrm{T}}[8]$, and Sulfobacillus acidophilus $\mathrm{NAL}^{\mathrm{T}}[9]$. Here, we report the first genome of a bacterium from the genus Crassaminicella. The availability of genome sequence will promote the understanding not only of bacteria from this genus but also the adaptation strategies of gram-positive bacteria to the deep-sea hydrothermal vent.

\section{Data description}

General features of this strain and the MIGS mandatory information are shown in Table 1. High-quality total genomic DNA was extracted using a MagAttract DNA kit (Qiagen, USA) according to the manufacturer's instructions. Whole genome sequence was obtained by sequencing using GridION platform (Nextomics, China). Over $3 \mathrm{~Gb}$ of processed reads were generated for an approximately 950-fold depth of coverage. Clean reads were assembled using Canu v1.7 to generate the complete genome sequence [10], and the results were corrected using Pilon v1.22 (https://github.com/broadinstitute/pilon) based on the MGI-SEQ 2000 sequence. Gene predictions were made using Prodigal v2.6.3 (https://github.com/hyattpd/Prodigal). Functional information for each predicted gene was obtained based on sequence-similarity search against the non-redundant protein database available from the National Center for Biotechnology Information, Clusters of Orthologous Groups (COG) database [11], Gene Ontology (GO) database [12], and Kyoto Encyclopedia of Genes and Genomes (KEGG) [13]. tRNA genes were predicted by using tRNA scan-SE v2.0 (http://lowelab.ucsc.edu/tRNAscan-SE). rRNA genes were predicted by 

predicted by using PHASTER web server (http://phaster.ca/). Presence of genomic islands was investigated by using Islander v1.2 program (https://bioinformatics.sandia.gov/islander) and CRISPR arrays were analyzed by using the Minced program v0.3.0 (https://github.com/ctSkennerton/minced). Circular representations of the SY095 genome were prepared by using Circos v1.7.11 (http://circos.ca/).

93

\begin{tabular}{|c|c|}
\hline Item & Description \\
\hline \multicolumn{2}{|l|}{ MIGS data } \\
\hline Project_name & Crassaminicella sp. SY095 genome sequencing \\
\hline Geographic location & Indian Ocean \\
\hline Latitude and longitude & $37^{\circ} 46^{\prime} 58.69^{\prime \prime} \mathrm{S}, 49^{\circ} 38^{\prime} 59.96^{\prime \prime} \mathrm{E}$ \\
\hline Water depth & $2730 \mathrm{~m}$ \\
\hline Collection date & $12-2018$ \\
\hline Environment (biome) & Ocean biome ENVO:01000048 \\
\hline Environment (feature) & Marine hydrothermal vent ENVO:01000122 \\
\hline Environment (material) & Marine hydrothermal vent chimney ENVO:01000129 \\
\hline $\begin{array}{l}\text { Observed biotic } \\
\text { relationship }\end{array}$ & Free living \\
\hline Trophic_level & Chemoheterotroph \\
\hline Sequencing method & Oxford Nanopore GridION \\
\hline Assembly method & Canu version 1.7 \\
\hline Coverage & $950.0 \mathrm{x}$ \\
\hline Finishing_strategy & Complete \\
\hline \multicolumn{2}{|l|}{ General feature } \\
\hline \multirow{6}{*}{ Classification } & Domain Bacteria \\
\hline & Phylum Firmicutes \\
\hline & Class Clostridia \\
\hline & Order Clostridiales \\
\hline & Family Clostridiaceae \\
\hline & Genus Crassaminicella \\
\hline Gram stain & Positive \\
\hline Cell shape & Rod \\
\hline Motility & Motile \\
\hline
\end{tabular}




\begin{tabular}{lll}
\hline Relationship to oxygen & Obligate anaerobe & \\
Optimal temperature & $50{ }^{\circ} \mathrm{C}$ & \\
Genomic features & Chromosome & Plasmid \\
Size (bp) & $3,046,753$ & 36,627 \\
G+C content $(\%)$ & 30.81 & 31.29 \\
Number of predicted CDSs & 2,907 & 59 \\
Genes assigned to COG & 1,959 & 8 \\
Number of rRNA genes & $12,11,11(5 \mathrm{~S}, 16 \mathrm{~S}, 23 \mathrm{~S})$ & 0 \\
Number of tRNAs & 135 & 0 \\
Number of CRISPRs & 2 & 0 \\
\hline
\end{tabular}

Table 1. General features and genome sequencing project information for Crassaminicella sp. SY095 according to MIGS recommendations

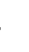

The strain SY095 genome contains a single circular chromosome (3,046,753 bp, $30.81 \% \mathrm{G}+\mathrm{C})$ and one circular plasmid $(36,627 \mathrm{bp}, 31.29 \% \mathrm{G}+\mathrm{C})$. Maps of the chromosome and plasmid are shown in Fig. 1. CheckM analysis affiliated it with Clostridiales and showed a high quality of the genome with a completeness of $97.87 \%$ and a contamination of $1.03 \%$. The genome codes eleven 16S rRNA genes with sequence identities higher than $98.9 \%$ between each other. Overall, 2966 protein-coding sequences (CDS) were predicted, which cover approximately $87.03 \%$ of the entire genome. The genome also contains 135 tRNA genes, 34 rRNA genes, and two CRISPR loci. No genomic island was identified. Approximately half CDSs were annotated using the COG (66.32\%), GO (58.23\%), and KEGG (50.23\%) databases. Upon COG classification, 1967 genes were assigned to 23 functional categories. The major categories were amino acid transport and metabolism (10.46\%); translation, ribosomal structure and biogenesis $(9.95 \%)$; signal transduction mechanisms (7.76\%); general function prediction only $(7.04 \%)$; transcription $(6.99 \%)$; cell wall/membrane/envelope biogenesis (6.33\%); coenzyme transport and 

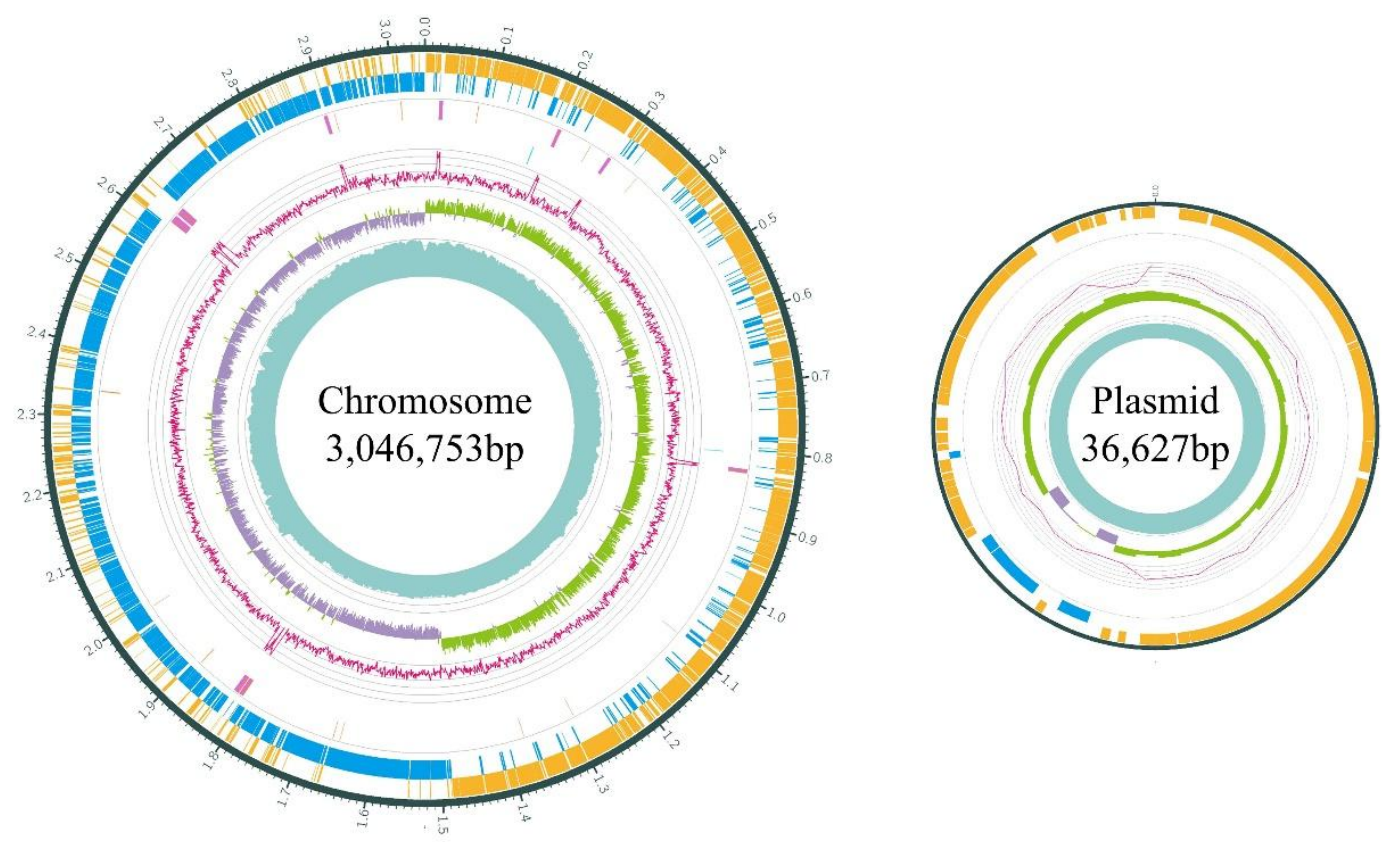

Fig. 1. Schematic representation of the Crassaminicella sp. SY095 genome. The genome comprises one chromosome and one plasmid. Labeling from the outside to

117 the center is as follows: circle 1, genes on the forward strand; circle 2, genes on reverse strand; circle 3, RNA genes (tRNAs orange, rRNAs purple); circle 4, CRISPRs (blue) and predicted genomic islands (green); circle 5, GC content; circle 6, GC skew; and circle 7, sequencing depth.

121 Viruses, especially phages, are the most abundant life forms in the deep-sea hydrothermal vent ecosystems, and have been proposed to play a pivotal role in the regulation of microbial abundance and metabolism, thus driving the biogeochemical cycles $[14,15]$. In addition to acting as microbial predators, phages might confer an enhanced level of fitness to the microbial host, enhancing host survival in the extreme 
environment [16]. In the strain SY095 genome, four putative prophages were identified, named CTV1 to CTV4. CTV1, CTV2, and CTV3 are integrated into the chromosome, while CTV4 exists in the form of an extrachromosomal plasmid (Table 2). The four prophage genomes contain all the genes necessary for viral particle synthesis and have similar gene organization. The prophage attachment sites (attL and $a t t R$ ) were detected at the ends of proviral sequences. In addition, large numbers of genes coding for functionally unknown proteins were identified in the prophage genomes, whose functions in phage-host interaction or adaptation of the host cells to extreme environments require further investigation.

\begin{tabular}{ccccc}
\hline Prophage & Size $(\mathrm{kb})$ & GC content & ORFs & Location \\
\hline CTV1 & 60.5 & $31.66 \%$ & 96 & chromosome \\
CTV2 & 56.6 & $31.53 \%$ & 93 & chromosome \\
CTV3 & 48.0 & $31.09 \%$ & 91 & chromosome \\
CTV4 & 36.6 & $31.28 \%$ & 59 & plasmid \\
\hline
\end{tabular}

Table 2. Predicted prophage clusters in Crassaminicella sp. SY095.

Strain SY095 forms terminal endospores at late stage of growth. SpoOE gene encodes an aspartyl-phosphate phosphatase that controls the precise timing and progression of sporulation [17]. Seven spoOE genes harboring a classical conserved motif were identified in the SY095 genome. Three of them were carried by chromosomal prophages CTV1, CTV2, and CTV3, while none was identified in the CTV4 prophage. It is therefore likely that auxiliary spoOE genes of prophages are involved in the sporulation of the host cell. However, the interaction among the prophages and their relationship with the host cell remains largely unknown. Further efforts will be 
147 Collectively, the complete genomic data of strain SY095 provides additional genetic

148 information for bacteria from the genus Crassaminicella and also contributes to the

required to elucidate their biological function and ecological roles, especially in the deep-sea hydrothermal vent environment. expansion of knowledge on microbial adaptations to the deep-sea hydrothermal vent environment.

\section{Genome sequence accession numbers}

The complete genome sequence of Crassaminicella sp. SY095 is available in the Genbank database (https://www.ncbi.nlm.nih.gov/genbank/) under the accession number CP042243 (Chromosome) and CP042244 (Plasmid). BioSample data is available in the NCBI BioSample database (http://www.ncbi.nlm.nih.gov/biosample/) under accession number SAMN12368985. The data have been deposited with links to BioProject accession number PRJNA556796 in the NCBI BioProject database (https://www.ncbi.nlm.nih.gov/bioproject/). The strain is available at Marine Culture Collection of China, MCCC (http://www.mccc.org.cn/) with accession number MCCC 1K04191.

\section{Acknowledgements}

This work was supported by grants from the National Key R\&D Program of China (2018YFC0309904, 2016YFC0304905, and 2016YFC0302502), the National Natural Science Foundation of China (NSFC 41806174, 91751202, and 91751108), and a grant for LIA0858-MagMC from the Centre National de la Recherche Scientifique. We are very grateful to all the participants of the TS10 cruise of R/V Tan Suo Yi Hao 
and the pilots of the Shen Hai Yong Shi for their professional service during this cruise. The LABGeM (CEA/Genoscope \& CNRS UMR8030), the France Génomique and French Bioinformatics Institute national infrastructures (funded as part of Investissement d'Avenir program managed by Agence Nationale pour la Recherche, contracts ANR-10-INBS-09 and ANR-11-INBS-0013) are acknowledged for support within the MicroScope annotation platform.

\section{Declarations of interest: none}

\section{References}

[1] G.J. Dick, The microbiomes of deep-sea hydrothermal vents: distributed globally, shaped locally, Nat Rev Microbiol, 17 (2019) 271-283.

[2] J. McNichol, H. Stryhanyuk, S.P. Sylva, F. Thomas, N. Musat, J.S. Seewald, S.M. Sievert, Primary productivity below the seafloor at deep-sea hot springs, P Natl Acad Sci USA, 115 (2018) 6756-6761.

[3] L.B. Nadine, M. Yucel, A. Das, S.M. Sievert, P.R. Girguis, Hydrothermal energy transfer and organic carbon production at the deep seafloor, Frontiers in Marine Science, 5 (2018) 531.

[4] J. Ding, Y. Zhang, H. Wang, H. Jian, H. Leng, X. Xiao, Microbial Community Structure of Deep-sea Hydrothermal Vents on the Ultraslow Spreading Southwest Indian Ridge, Front Microbiol, 8 (2017) 1012.

[5] H.L. Cao, Y. Wang, O.O. Lee, X. Zeng, Z.Z. Shao, P.Y. Qian, Microbial Sulfur Cycle in Two Hydrothermal Chimneys on the Southwest Indian Ridge, Mbio, 5 (2014).

[6] R. Lakhal, N. Pradel, A. Postec, B. Ollivier, J.L. Cayol, A. Godfroy, M.L. Fardeau, G. Gales, Crassaminicella profunda gen. nov., sp. nov., an anaerobic marine bacterium isolated from deep-sea sediments, Int J Syst Evol Microbiol, 65 (2015) 3097-3102.

[7] G.B. Slobodkina, T.V. Kolganova, T.P. Tourova, N.A. Kostrikina, C. Jeanthon, E.A. Bonch-Osmolovskaya, A.I. Slobodkin, Clostridium tepidiprofundi sp. nov., a moderately 
thermophilic bacterium from a deep-sea hydrothermal vent, Int J Syst Evol Microbiol, 58 (2008) $852-855$

[8] S. L'Haridon, M.L. Miroshnichenko, N.A. Kostrikina, B.J. Tindall, S. Spring, P. Schumann, E. Stackebrandt, E.A. Bonch-Osmolovskaya, C. Jeanthon, Vulcanibacillus modesticaldus gen. nov., sp. nov., a strictly anaerobic, nitrate-reducing bacterium from deep-sea hydrothermal vents, Int $\mathbf{J}$ Syst Evol Microbiol, 56 (2006) 1047-1053.

[9] P.R. Norris, D.A. Clark, J.P. Owen, S. Waterhouse, Characteristics of Sulfobacillus acidophilus sp. nov. and other moderately thermophilic mineral-sulphide-oxidizing bacteria, Microbiology, 142 ( Pt 4) (1996) 775-783.

[10] S. Koren, B.P. Walenz, K. Berlin, J.R. Miller, N.H. Bergman, A.M. Phillippy, Canu: scalable and accurate long-read assembly via adaptive k-mer weighting and repeat separation, Genome Res, 27 (2017) 722-736.

[11] M. Galperin, K. Makarova, Y. Wolf, E. Koonin, Expanded microbial genome coverage and improved protein family annotation in the COG database. Nucleic Acids Res43: D261-D269, 2015.

[12] M. Ashburner, C.A. Ball, J.A. Blake, D. Botstein, H. Butler, J.M. Cherry, A.P. Davis, K. Dolinski, S.S. Dwight, J.T. Eppig, M.A. Harris, D.P. Hill, L. Issel-Tarver, A. Kasarskis, S. Lewis, J.C. Matese, J.E. Richardson, M. Ringwald, G.M. Rubin, G. Sherlock, G.O. Consortium, Gene Ontology: tool for the unification of biology, Nat Genet, 25 (2000) 25-29.

[13] M. Kanehisa, S. Goto, Y. Sato, M. Kawashima, M. Furumichi, M. Tanabe, Data, information, knowledge and principle: back to metabolism in KEGG, Nucleic Acids Res, 42 (2014) D199-205. [14] E. Rastelli, C. Corinaldesi, A. Dell'Anno, M. Tangherlini, E. Martorelli, M. Ingrassia, F.L. Chiocci, M. Lo Martire, R. Danovaro, High potential for temperate viruses to drive carbon cycling in chemoautotrophy-dominated shallow-water hydrothermal vents, Environmental microbiology, 19 (2017) 4432-4446.

[15] H.G. Castelan-Sanchez, I. Lopez-Rosas, W.A. Garcia-Suastegui, R. Peralta, A.D.W. Dobson, R.A. Batista-Garcia, S. Davila-Ramos, Extremophile deep-sea viral communities from hydrothermal vents: Structural and functional analysis, Mar Genomics, 46 (2019) 16-28.

[16] T. He, H. Li, X. Zhang, Deep-sea hydrothermal vent viruses compensate for microbial 
222 metabolism in virus-host interactions, Mbio, 8 (2017) e00893-00817.

223 [17] G.P. Dubey, A. Narayan, A.R. Mattoo, G.P. Singh, R.K. Kurupati, M.S. Zaman, A. Aggarwal,

224 R.B. Baweja, S. Basu-Modak, Y. Singh, Comparative genomic study of spoOE family genes and 225 elucidation of the role of Spo0E in Bacillus anthracis, Archives of Microbiology, 191 (2009) $226 \quad 241-253$. 